J Ästhet Chir 2012 · 4:150-151 · DOI 10.1007/s12631-012-0179-y

Online publiziert: 29 . September 2012

U. Schaudig $\cdot$ P. Heidari S. Schumacher

Augenklinik, Asklepios Klinik Barmbek, Hamburg

\title{
Erratum zu: Ektropium und Entropium des Unterlids
}

Indikation, Technik und Schlüsselpunkte

„klassischer" Operationsmethoden

J Ästhet Chir (2011) 4:173-180

http://dx.doi.org/10.1007/s12631-011-0135-2

In diesem Beitrag wurden leider

- Abb. 1 und 3 vertauscht. Die Technik für den Absatz „Tarsokonjunktivale Exzision, invertierende Naht und horizontale Kürzung des Lids“ wird in der umbenannten • Abb. 1 erläutert.

Unter dem Absatz „Horizontale Lidspaltung mit evertierender Naht und horizontaler Lidkürzung" wird die Methode in $\bullet$ Abb. 3 dargestellt.

Wir bitten zukünftig diese Korrektur zu berücksichtigen und den Fehler zu entschuldigen.
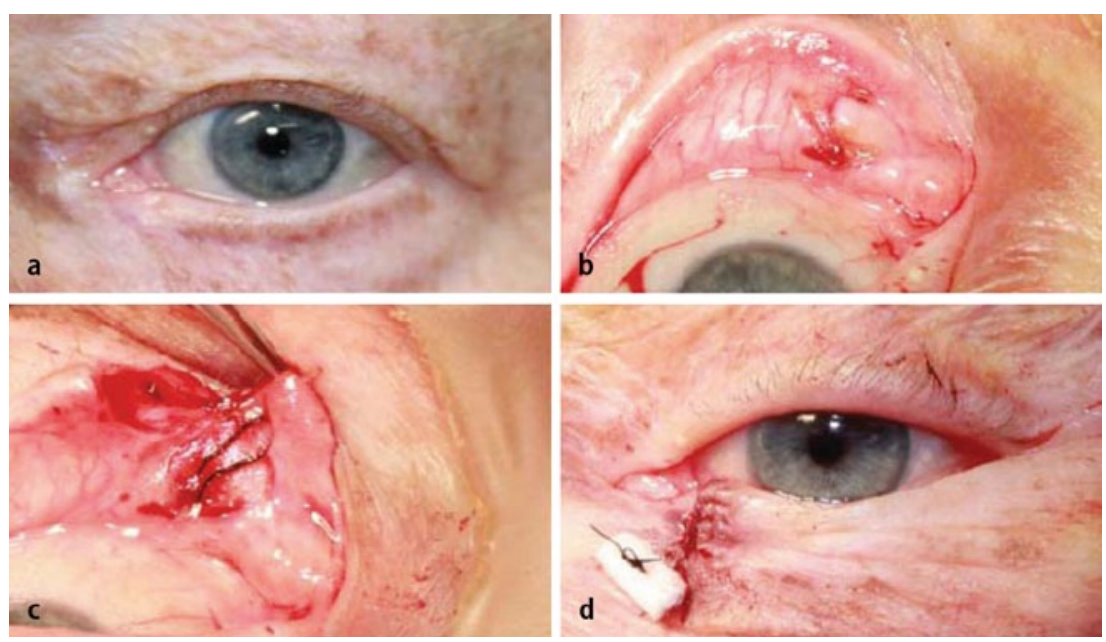

Abb. 1 А Horizontale Lidstraffung, rautenförmige Exzision und invertierende Naht („lazy-T“). a Mediales Ektropium bei straffen Lidbändchen, aber horizontaler Erschlaffung. b Rautenförmige Exzision unter dem Tränenpünktchen. c Invertierende Naht. $\mathbf{d}$ Lidkantenverschluss und invertierende Naht über einem Polster 

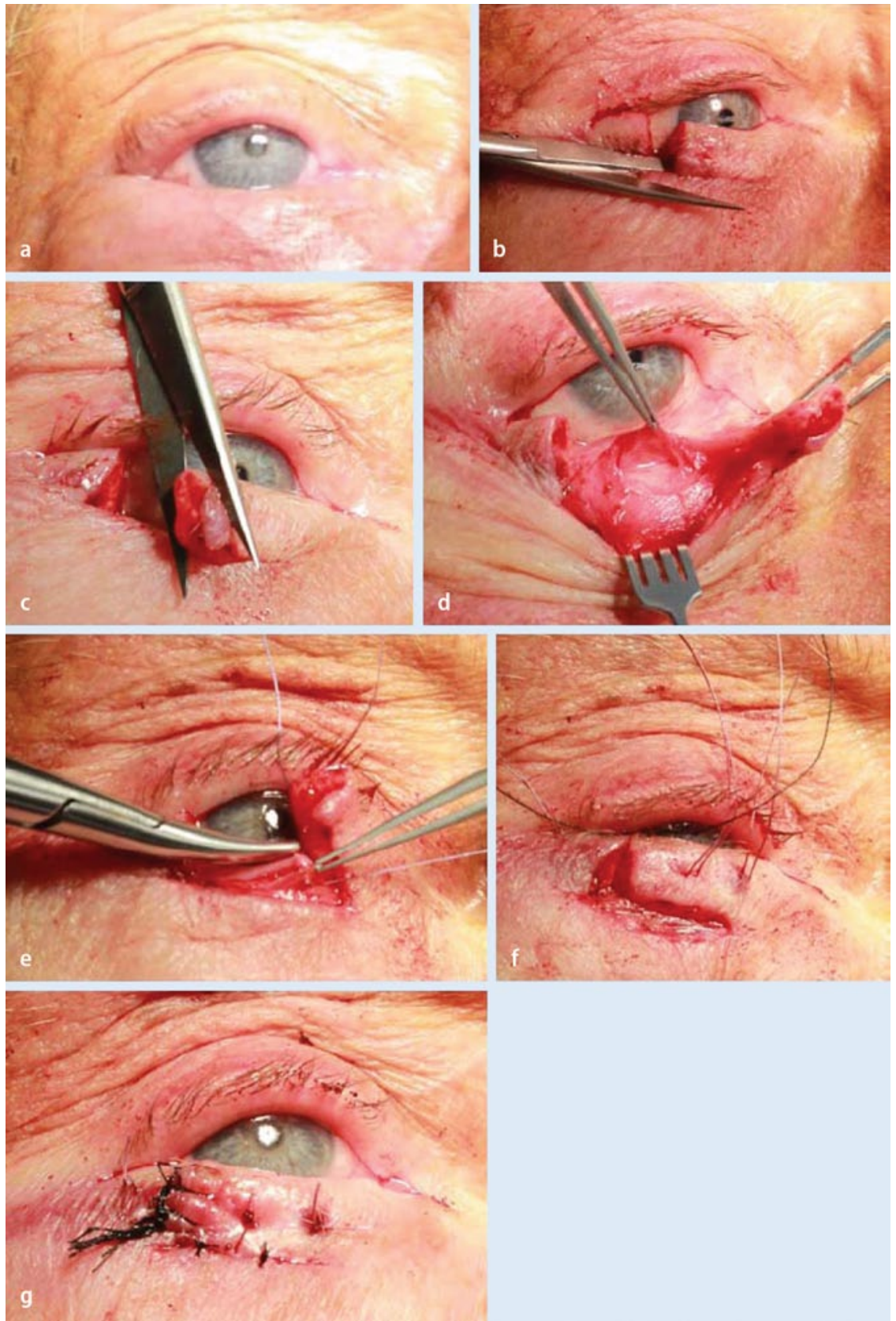

Abb. $3 \Delta$ Horizontale Lidkürzung, horizontale Lidspaltung und evertierende Naht. a Unterlidentropium (Unterlid komplett invertiert, keine Wimpern sichtbar). b Horizontaler Schnitt durch alle Lidschichten. c $90^{\circ}$-Inzision zur Lidkante und Lidkantenexzision zur horizontalen Straffung. Das Auge kann - und sollte bei Anfängern - mit einer Schutzschale geschützt werden. $\mathbf{d}$ Identifikation. e Fassen der Lidretraktorenschicht mit der evertierenden Naht. f Anlegen der evertierenden und Lidkantennähte. g Vollständige Naht 